\title{
ANALISIS STRATEGI DAN PENGEMBANGAN PRODUK UNGGULAN PADA INDUSTRI KECIL MENENGAH BAHAN KACA DI MALANG
}

\author{
Purnomo, Rudy Setiawan, dan Felik Sad Wisnu \\ Program Studi Teknik Industri Universitas Ma Chung \\ Jl. Villa Puncak Tidar N 01 Malang \\ e-mail: pur.nomo@machung.ac.id
}

\begin{abstract}
ABSTRAK
Kota Malang memiliki potensi untuk memasarkan produk-produk unggulan di Indonesia bentuk industri kecil. Untuk memasarkan produk perlu sarana informasi agar publik tahu untuk hasil kinerja produk yang unggul dari industri skala kecil seperti: kerajinan bahan kaca, kerajinan mebel kayu, kripik tempe dan lainnya. Penelitian ini bertujuan untuk menganalisis bagaimana strategi pengembangan usaha kecil home industry kerajinan bahan kaca dengan menggunakan alat analisis SWOT untuk menganalisis kekuatan (strenghts), kelemahan (weaknesses), peluang (opportunities), dan ancaman (threats). Hasil dari produk unggulan industri kecil adalah penulis fokus pada industri kecil menengah daur ulang bahan kaca daerah pemasaran di sekitar Probolinggo, Sidoarjo, Pasuruan dll. Kerajinan daur ulang bahan kaca untuk daerah pemasaran Probolinggo, Bali dan Surabaya dianggap perlu memegang produk pengembangan (Product Development), yang bertujuan untuk meningkatkan daya saing industri kecil di kelas yang sama. Akhirnya dari hasil penelitian didapat beberapa pencapaian penting meliputi: (1) Peningkatan permintaan pasar, (2) Kesinambungan produk, (3) Peningkatan produktivitas, (4) Harga pokok dapat ditekan, (5) Pengoperasian pendapatan meningkat.
\end{abstract}

Kata kunci: IKM, Product Development, Bahan Kaca, SWOT.

\section{ABSTRACT}

Malang City has the potential to market superior products in Indonesia in the form of small industries. To market products, information facilities are needed so that the public knows the results of superior product performance from small-scale industries such as: glass material crafts, wood furniture crafts, tempe chips and others. This study aims to analyze how the strategy of developing small home industries of glass handicraft industries using SWOT analysis tools to analyze strengths, weaknesses, opportunities, and threats. The results of the superior products of small industries are the authors focus on small and medium industries recycling glass materials marketing areas around Probolinggo, Sidoarjo, Pasuruan etc. Recycled glass craft for the marketing areas of Probolinggo, Bali and Surabaya, it is deemed necessary to hold product development (Product Development), which aims to increase the competitiveness of small industries in the same class. Finally, the results of the study found several important achievements include: (1) Increasing market demand, (2) Product sustainability, (3) Increasing productivity, (4) Cost of goods can be reduced, (5) Operating income increases.

Keywords: IKM, Product Development, Glass Material, SWOT.

\section{PENDAHULUAN}

Usaha kecil mempunyai peran penting dalam pertumbuhan ekonomi suatu Negara. Pengembangan usaha kecil di Indonesia merupakan salah satu prioritas dalam pembangunan ekonomi nasional. Ini karena usaha tersebut merupakan tulang punggung sistem ekonomi kerakyatan yang tidak hanya ditujukan untuk mengurangi masalah kesenjangan antar golongan pendapatan dan antar pelaku usaha, lebih dari itu pengembangannya mampu memperluas basis ekonomi dan dapat memberikan kontribusi yang signifikan dalam mempercepat perubahan struktural. Yakni meningkatnya perekonomian dan ketahanan ekonomi nasional. Melihat potensi industri yang sangat baik, tidak berarti dalam proses usahanya tidak menghadapi hambatan dan tantangan. Usaha kecil menghadapi berbagai tantangan dan kendala seperti kualitas sumber daya manusia yang rendah; tingkat produktifitas dan kualitas produk dan jasa rendah; kurangnya 
teknologi dan informasi; faktor produksi; sarana; dan prasarana belum memadai; aspek pendanaan dan pelayanan jasa pembiayaan; iklim usaha belum mendukung; dan koordinasi pembinaan belum baik [1]. Namun demikian ada peluang yang dapat dimanfaatkan oleh UKM dalam kegiatan usahanya, seperti: adanya komitmen pemerintah; ketersediaan sumber daya alam yang beranekaragam dan lain-lain. Permasalahan akses modal yang lemah, produktivitas rendah, kemampuan pengelolaan usaha yang masih sederhana, akses untuk mendapatkan teknologi modern dan beban birokrasi turut memberikan permasalahan bagi sektor UMKM [2]. Sektor UKM sendiri dibagi ke dalam beberapa kategori. Berdasarkan karakteristik pemiliknya; berdasarkan organisasi pemiliknya; berdasarkan prioritas strategi; dan berdasarkan skala ekonomi [3].

\section{STRATEGI PEMASARAN}

Manajemen strategis adalah seni dan ilmu untuk pembuatan (formulating), penerapan (implementing) dan evaluasi (evaluating) keputusan-keputusan antar fungsi yang memungkinkan sebuah organisasi mencapai di masa yang akan datang [4]. Strategi pemasaran memerlukan keputusan-keputusan dari manajemen tentang elemen-elemen marketing mix perusahaan. Sedangkan taktik itu hanya merupakan program tertentu untuk jangka pendek saja. Kedua istilah strategi dan taktik tersebut sama-sama menghendaki keputusan-keputusan di bidang perencanaan barang, penetapan harga, distribusi, dan promosi (Gambar 1).

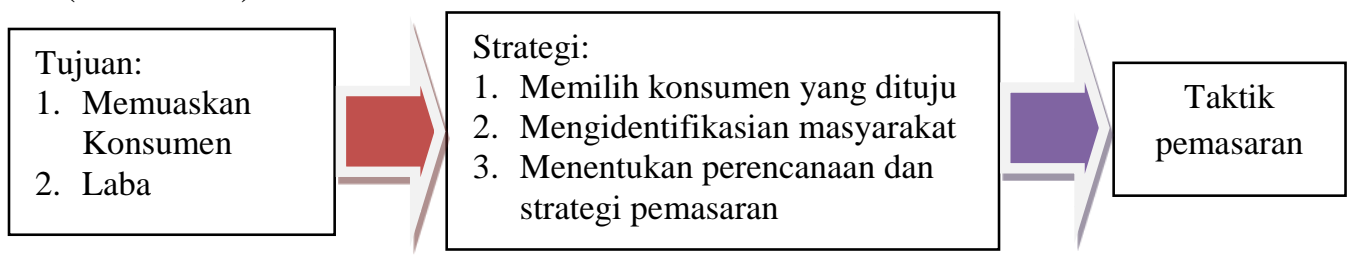

Gambar 1. Hubungan Tujuan, Strategi, dan Taktik Pemasaran

Strategi adalah suatu rencana yang diutamakan untuk mencapai tujuan, Dalam pemasaran, strategi yang ditempuh oleh pengusahaterdiri dari 3 (tiga) tahap, yaitu: (1) memilih konsumen, (2) mengidentifikasi keinginan pelanggan, (3) menentukan marketing mix [5].

\section{PENGEMBANGAN PRODUK}

Kotler dalam bukunya Marketing Management [6] mengemukakan bahwa ada delapan proses pengembangan produk baru yaitu mencakup: pemunculan gagasan (idea generation), penyaringan gagasan (idea screening), pengembangan dan pengujian konsep (concept development and testing), pengembangan strategi pemasaran (marketing strategy development), analisis bisnis (business analysis), pengembangan produk (product development), pengujian pasar (market testing), dan komersialisasi (commercialization).

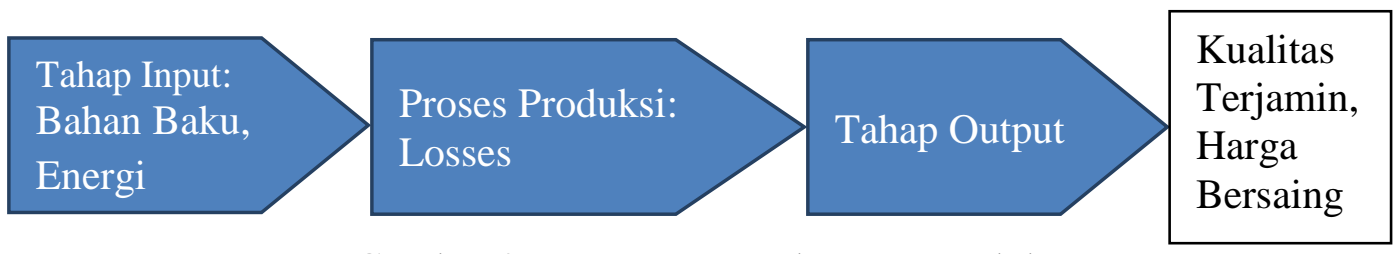

Gambar 2. Proses Pengembangan Produk

Pada Gambar 2 bahan terdiri dari input - proses produksi - output apabila hal tersebut terjadi dengan sempurna maka perlu dilakukan pengembangan produk (product development) dengan beberapa alasan dan pertimbangan bahwa kontinyuitas pesanan terjamin, kualitas sesuai dan daya beli terjangkau. 


\section{METODE}

Penelitian ini menggunakan data primer. Data primer dikumpulkan langsung melalui observasi (pengamatan), dengan menggunakan kuesioner yang telah disiapkan sebelumnya. Dalam penelitian ini, sumber datanya adalah pemilik industri kecil kerajinan daur ulang bahan kaca di Kota Malang. Adapun variabel dalam penelitian ini adalah Profil usaha industri kecil kerajinan daur ulang bahan kaca di Kota Malang. mencakup; SDM (Tenaga Kerja) indikatornya: Jumlah tenaga kerja, tingkat pendidikan, dan usia tenaga kerja. Permodalan indikatornya modal awal dan sumber modal, Teknologi indikatornya: teknologi yang digunakan, Pemasaran indikatornya: daerah pemasaran dan promosi yang dilakukan dan Bahan Baku.

Analisis data dalam penelitian menggunakan metode analisis deskriptif. Di mana metode ini merupakan cara merumuskan dan menafsirkan data yang ada sehingga memberikan gambaran yang jelas mengenai profil industri kecil kerajinan bahan kaca dan faktor internal dan eksternal industri kecil kerajinan daur ulang bahan kaca di Kota Malang. Selanjutnya analisis SWOT. Fungsinya adalah identifikasi berbagai faktor secara sistematis untuk merumuskan faktor-faktor pendorong dan penghambat pertumbuhan dan perkembangan sektor industri kecil kerajinan daur ulang bahan kaca. Analisis ini didasarkan pada logika yang dapat memaksimalkan kekuatan (strength) dan peluang (opportunities), namun secara bersamaan dapat meminimalkan kelemahan (weakness) dan ancaman (treats). Berikut Tabel 1, Tabel 2 dan Tabel 3 dan Gambar 3 adalah langkahlangkah analisis mengenai kekuatan, kelemahan, peluang, dan ancaman pada sektor industri kecil kerajinan daur ulang bahan kaca.

Tabel 1. Analisis Faktor Internal dan Eksternal

\begin{tabular}{|c|c|c|c|}
\hline $\begin{array}{l}\text { Faktor-faktor Strategi } \\
\text { Internal dan Eksternal }\end{array}$ & Bobot & Rating & Bobot x Rating \\
\hline Kekuatan & & & \\
\hline Kelemahan & & & \\
\hline Peluang & & & \\
\hline Ancaman & & & \\
\hline
\end{tabular}

Pemberian bobot masing-masing skala mulai 1,0 (paling penting) sampai 0,0 (paling tidak penting), berdasarkan pengaruh tersebut. Semua bobot tersebut tidak boleh melebihi skor total 1,00. Pemberian rating untuk masing-masing faktor-faktor dengan skala mulai dari empat sampai dengan satu, berdasarkan pengaruh faktor tersebut terhadap kondisi sektor industri kecil kerajnan bahan kaca.

Tabel 2. Alternatif Pengembangan SWOT secara Matrik

\begin{tabular}{|c|c|c|}
\hline Faktor Interns & Kekuatan (S) & Kelemahan (W) \\
\hline Peluang (O) & $\begin{array}{l}\text { Kekuatan yang ada digunakan } \\
\text { untuk mengisis peluang yang } \\
\text { tersedia (SO) }\end{array}$ & $\begin{array}{l}\text { Memanfaatkan peluang yang ada } \\
\text { dengan menanggulangi } \\
\text { kelemahannya (WO) }\end{array}$ \\
\hline Ancaman (T) & $\begin{array}{l}\text { Kekuatan yang dimiliki untuk } \\
\text { mengatasi ancaman yang dihadapi } \\
\text { (ST) }\end{array}$ & $\begin{array}{l}\text { Meminimalkan kelemahan dan } \\
\text { menghindari ancaman (WT) }\end{array}$ \\
\hline
\end{tabular}




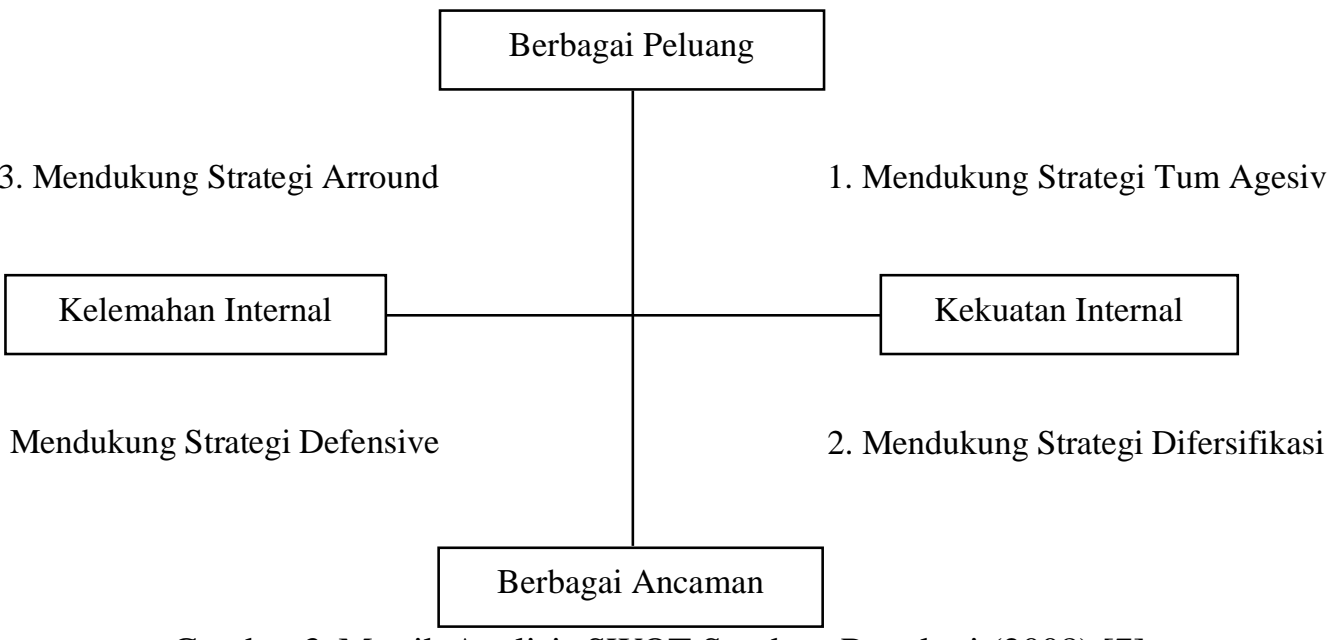

Gambar 3. Matrik Analisis SWOT Sumber: Rangkuti (2008) [7]

Tabel 3. Matriks SWOT

\begin{tabular}{lll}
\hline \multicolumn{1}{c}{ IFAS } & Kekuatan $(\mathbf{S})$ & Kelemahan $(\mathbf{W})$ \\
& Daftar kekuatan & Daftar kelemahan \\
\hline Peluang (O) & S - O & W - O \\
Daftar peluang & Strategi Gunakan kekuatan untuk & Strategi Memperkecil kelemahan \\
& Meraih peluang & dengan Memanfaatkan peluang \\
Ancaman (T) & S - T & W - T \\
Daftar ancaman & Strategi Gunakan kekuatan untuk & Strategi Memperkecil kelemahan \\
& menghindari ancaman & dan menghindari ancaman \\
\hline
\end{tabular}

\section{HASIL DAN PEMBAHASAN}

Unit usaha industri kecil kerajinan bahan kaca di Kota Malang mempunyai pengembangan yang sangat pesat. Ditinjau dari segi permodalan, hasil penelitian menunjukkan bahwa sebagian besar sumber modal industri kecil kerajinan daur ulang bahan kaca di Kota Malang berasal dari modal sendiri atau pribadi. Tabel 4 dan Tabel 5 adalah hasil matrik faktor strategi internal dan eksternal. Rating dan pembobotannya dalam Gambar 4 dan 5. Tabel 6 adalah hasil matriks SWOT strategi pengembangan sentra IKM Daur Ulang Sampah Bahan Kaca di Malang.

Tabel 4. Matrik Faktor Strategi Internal kerajinan Bahan Kaca Malang

\begin{tabular}{|c|c|c|c|c|}
\hline 1 & Faktor Strategi Internal & Bobot & Rating & B x R \\
\hline & \multicolumn{4}{|l|}{ Kekuatan } \\
\hline & Bahan baku kaca mudah didapat & 0.10 & 4 & 0.40 \\
\hline & SDM Lebih murah & 0.10 & 4 & 0.40 \\
\hline & Modal sendiri & 0.20 & 4 & 0.80 \\
\hline & Keterampilan bekerja tingi & 0.05 & 3 & 0.15 \\
\hline & Kecukupan tenaga kerja & 0.05 & 3 & 0.15 \\
\hline & Sub Total & 0.50 & & 1.90 \\
\hline & \multicolumn{4}{|l|}{ Kelemahan } \\
\hline & Keterbatasan SDM & 0.05 & 2 & 0.10 \\
\hline & Masih minimnya pengetahuan alat daur ulang bahan kaca & 0.05 & 2 & 0.10 \\
\hline & Minimnya area kerja di Malang & 0.15 & 2 & 0.30 \\
\hline & Sulitnya kerjasama dengan pemkot & 0.15 & 1 & 0.15 \\
\hline & Minimnya Kemampuan memperluas cakupan dan akses pasar & 0.10 & 1 & 0.10 \\
\hline & Sub Total & 0.50 & & 0.75 \\
\hline & Total & 1.00 & & 2.65 \\
\hline
\end{tabular}


Tabel 5. Matrik Faktor Strategi Eksternal kerajinan Bahan Kaca Malang

\begin{tabular}{|c|c|c|c|c|}
\hline 1 & Faktor Strategi Internal & Bobot & Rating & $\mathbf{B} \times \mathbf{R}$ \\
\hline & \multicolumn{4}{|l|}{ Peluang } \\
\hline & Peluang pasar luar daerah masih terbuka & 0.15 & 4 & 0.60 \\
\hline & Pengembangan Kota Malang terbuka & 0.15 & 4 & 0.60 \\
\hline & Potensi pengembangan produk cukup besar & 0.15 & 3 & 0.45 \\
\hline & $\begin{array}{l}\text { Perhatian pemerintah pusat pada IKM bahan kaca cukup } \\
\text { besar }\end{array}$ & 0.05 & 4 & 0.20 \\
\hline & Memiliki pasar yang potensial untuk bertumbuh & 0.05 & 4 & 0.15 \\
\hline & Sub Total & 0.55 & & 2.00 \\
\hline & \multicolumn{4}{|l|}{ Ancaman } \\
\hline & Adanya kompetitor & 0.05 & 2 & 0.10 \\
\hline & Aktifitas promosi kompetitor & 0.05 & 2 & 0.10 \\
\hline & Tingginya harga BBM & 0.10 & 1 & 0.15 \\
\hline & Pemberdayaan UKM tidak berpihak & 0.15 & 2 & 0.30 \\
\hline & \multirow[t]{3}{*}{ Tingginya Biaya dalam pengembangan IKM } & 0.10 & 2 & 0.20 \\
\hline & & 0.45 & & 0.75 \\
\hline & & 1.00 & & 2.75 \\
\hline
\end{tabular}

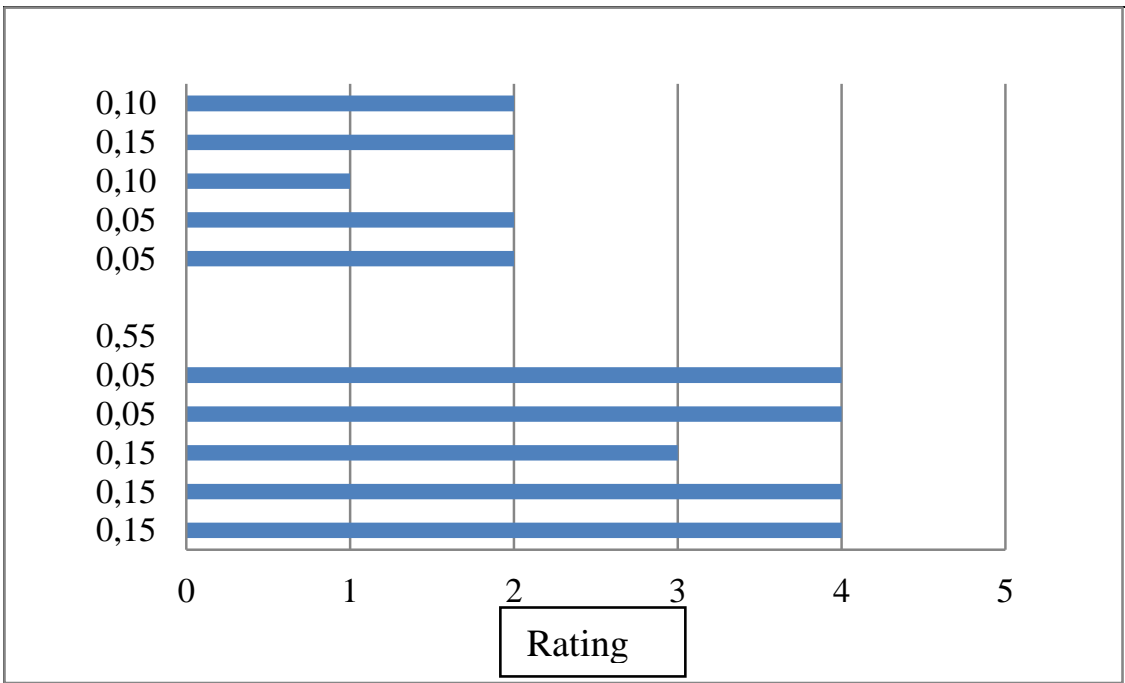

Gambar 4. Faktor Strategi Internal kerajinan Bahan Kaca

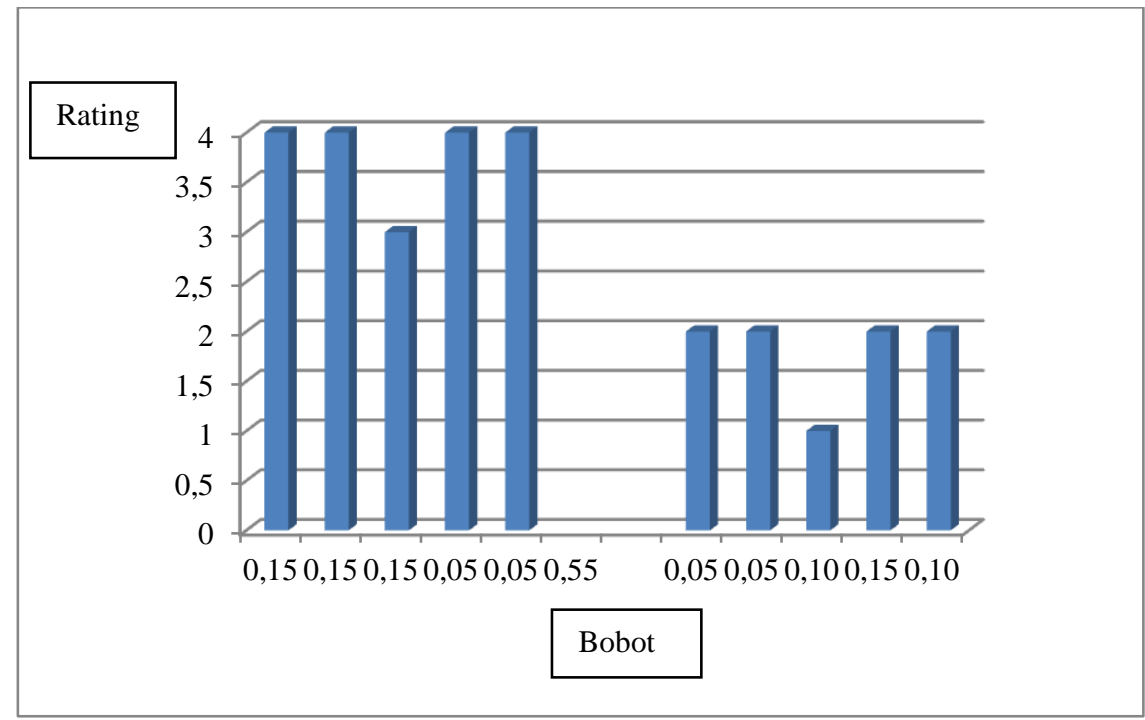

Gambar 5. Faktor Strategi Eksternal kerajinan Bahan Kaca 
Tabel 6. Hasil Matriks SWOT Strategi Pengembangan Sentra IKM

Daur Ulang Sampah Bahan Kaca di Malang

\begin{tabular}{|c|c|c|}
\hline IFAS & STRENGHT (S) 1,90 & WEAKNESSES (W) 0,75 \\
\hline EFAS & Faktot-faktor kekuatan Internal & Faktot-faktor kelemahan Internal \\
\hline OPPORTUNIES (O) & STRATEGI SO & STRATEGI WO \\
\hline Faktor peluang Eksternal & $\begin{array}{l}\text { Strategi yang menggunakan } \\
\text { kekuatan untuk memanfatkan } \\
\text { peluang jangka pendek menengah }\end{array}$ & $\begin{array}{l}\text { Strategi yang meminimalkan } \\
\text { kelemahan untuk memanfaatkan } \\
\text { peluang jangka panjang }\end{array}$ \\
\hline TREATHS (T) & STRATEGI ST & STRATEGI WT \\
\hline Faktor ancaman Eksternal & $\begin{array}{l}\text { Strategi yang menggunakan } \\
\text { kekuatan untuk mengatasi } \\
\text { ancaman jangka pendek }\end{array}$ & $\begin{array}{l}\text { Strategi yang meminimalkan } \\
\text { kelemahan dan menghindari } \\
\text { ancaman jangka menengah dan } \\
\text { panjang }\end{array}$ \\
\hline
\end{tabular}

\section{KESIMPULAN}

Berdasarkan analisis SWOT Tabel 6 ditemukan bahwa: kekuatan kerajinan bahan kaca kota Malang adalah kualitas bahan baku sesuai dengan standar, hasil produk kerajinan tangan yang bagus, berorientasi pada pelanggan, rata-rata SDM berketerampilan tinggi, harga jual produk, yang relatif sama dengan pesaing, jangkauan pemasaran yang luas. Kelemahan kerajinan bahan kaca adalah penggunaan teknologi masih sederhana, variasi model masih sedikit, belum mencoba hasil penelitian dan pengembangan usaha, upah tenaga kerja masih dibawah UMR, tidak pernah melakukan pelatihan tenaga kerja. Peluang IKM kerajinan bahan kaca adalah dukungan peraturan daerah yang cukup baik, pelayanan aparatur pemerintah cukup baik, kondisi, inovasi teknologi, dukungan teknologi yang baru terhadap produksi. Ancaman, persaingan bisnis yang ketat, daya beli masyarakat yang masih rendah, upah tenaga kerja yang rendah. Akhirnya dari hasil penelitian didapat beberapa pencapaian penting meliputi: (1) peningkatan permintaan pasar, (2) kesinambungan produk, (3) peningkatan produktivitas, (4) Harga pokok dapat ditekan, (5) Pengoperasian pendapatan meningkat yang signifikan.

\section{DAFTAR PUSTAKA}

[1]. Anoraga, Pandji., 2007, Pengantar Bisnis: Pengelolaan Bisnis dalam Era Globalisasi, Jakarta: Rineka Cipta.

[2]. Bustaman, Umi Salwa Ahmad., 2010, Growth Strategies among Small and Medium Enterprises - Case of Malaysia Entrepreneurs. Journal International of Small Business Management, 36 Issue 4.

[3]. Kitching, Jhon., David Smallbone, 2012, Are Freelancer A Neglected Form Of Micro, Small Business. International Journal of Small Business and Enterprise Development, Vol. 19 Issue: 1.

[4]. Umar, H., 2008, Manajemen Stretegi in Action. PT. Gramedia Pustaka Utama, Jakarta.

[5]. Abdul Haris ,2013, Pengembangan Produk Unggulan Industri Kecil Dan Strategi Pemasaran Berbasis Analisis SWOT Pada Industri Kecil Genteng, Kayu Mebel,dan Bordir di Kabupaten Probolinggo, Jurnal EcoBuss. Vol. 1, No 1 Maret 2013 Universitas Panca Maga Probolinggo.

[6]. Kotler, 2003. Marketing Management, Analysis, Planning and Controle. Edisi kelima. Prentice-Hall.

[7]. Rangkuti, Freddy., 2008, Analisis SWOT Teknik Membedah Kasus Bisnis. Jakarta: PT. Gramedia Pustaka Utama. 